\title{
Prospects of library use data integration in campus information systems: A glocalized perspective
}

\author{
Stavroula Sant-Geronikolou; Daniel Martínez-Ávila
}

How to cite this article:

Sant-Geronikolou, Stavroula; Martínez-Ávila, Daniel (2019). “Prospects of library use data integration in campus information systems: A glocalized perspective". El profesional de la información, v. 28, n. 4, e280410. https://doi.org/10.3145/epi.2019.jul.10

Manuscript received on $10^{\text {th }}$ March 2019 Accepted on $6^{\text {th }}$ June 2019

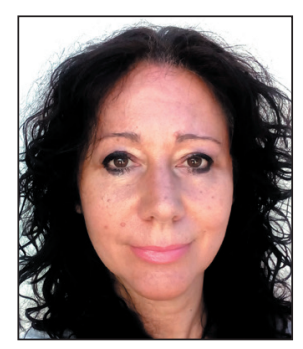

Stavroula Sant-Geronikolou $\square$ http://orcid.org/0000-0002-4340-7463

University Carlos III of Madrid Department of Librarianship and Information Science Madrid, 126. 28903 Getafe (Madrid), Spain liasantdsv@gmail.com

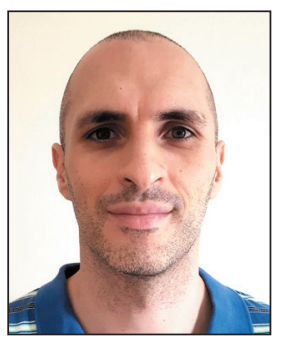
Daniel Martínez-Ávila http://orcid.org/0000-0003-2236-553X

São Paulo State University (Unesp) Department of Information Science Av. Hygino Muzzi Filho, 737. 17.525-900 - Marília, SP, Brazil dmartinezavila@gmail.com

\begin{abstract}
The study seeks to investigate the stakeholders' perceptions of organizational forces and operational issues that weigh upon the academic library's data capabilities, with a special focus on the Greek academic librarians' appreciation of the prospects of library use data integration in campus information systems. Findings from online interviews with international learning analytics experts and Greek academic library directors, that aimed to record their viewpoints around difficulties of integrating library data into learning analytics systems, brought to light several interpretative, organizational culture, librarian professional development, and user buy-in concerns. Interviewees made several recommendations related to collective action, training, and communications also stressing the importance of institutional support and active involvement of professional associations. The analysis of the participants' perspective provides a solid conceptual foundation for interpreting local issues associated with library use data capitalization within and beyond intra-institutional initiatives in the overarching goal to contribute actionable data to the development of context-specific tailor-made solutions.
\end{abstract}

\section{Keywords}

Academic libraries; Data; Library use; Learning analytics; Higher education; University; Metrics; Perceptions; Campus information systems; Organizational culture; Professional development; Prospects; Recommendations; Solutions; Greece.

\section{Theoretical framework}

\subsection{The changing circumstances of higher education}

"Technology is at the center of much of the turbulence in our times. It will also be among the solutions that help us weather this period." Picciano, Anthony G. (2012, p. 9)

Social transformations and the transition to the knowledge-based economy are today driving a shift in how value is created and perceived. This reality, in combination with the fact that learning is no longer seen as an individual process, has increased the need for enhancing the relevance of learning and teaching by supporting and promoting pedagogical innovation based on the exploitation of digital technologies. ${ }^{1}$

\section{Acknowledgements}

The authors would like to thank all participants for their valuable contributions. 
As knowledge is crafted in a contextualized space (Kincheloe, 2005), learning is no longer happening solely in the classroom, and the divisions between learning, work, and recreation are becoming increasingly blurred. Within this realm, educational theorists and higher education (HE) leaders started to wonder whether pedagogies are adequate to engage and educate the current generation of students (Farkas, 2012). They have also begun to reexamine the need for integration of new roles and to advocate for a change in both the culture of learning from separatism to seamlessness (Kezar, 2003), and librarian identity (Gregory; Lodge, 2015) under the influence of the progressivist and social constructivist educational ideologies (Trowler; Wareham, 2008). However, this shift from teacher-centered to student-centered learning can occasionally be uncomfortable for both academic and non-academic personnel due to the complexities and challenges involved (Scott, 2015).

No matter how much institutions may differ in how they engage students (Pike; Kuh, 2005; Trowler, 2010), the growing complexity and the new dynamics dictate the exploration of information technology-driven solutions to help better understand, monitor, and promote student engagement ${ }^{2}$ (Trowler, 2010). They also call for increased specialization and collaboration, customization, hybridity, and blending in strategies, structures, services, systems, spaces, and skills in higher education institutions (Van-Trigt, 2016) as learning according to Krause (2011 cited in Thomas, 2012, p. 47) "occurs in a range of settings, both within and beyond the formal curriculum".

These new circumstances have subsequently led the university community to acknowledge the "massive power and potential" of big data that make data collection tasks easier and faster. Administrators gradually came to understand that developing an analytics-friendly culture would enable their institutions to move beyond simply counting and compiling statistical measures (Cox; Jantti, 2012; Chen et al., 2015) to effectively tackle the challenges that they face today (Cormack, 2016). The inclusion and analysis of big data in educational contexts from a variety of digital and physical world sources such as libraries and tu-

Library administrators are increasingly becoming involved in the broad conversation about the potential of big data in educational contexts

tors resulting in a more complete learner profile, could help understand student engagement, and inform enhancements to the content. However, the set of ethical and practical considerations related to the implementation of such practices, in addition to the lack of investment in terms of both funds and staff (Brooks; Thayer, 2016) has stunted the growth of institutional analytics efforts. No matter how ready institutions may appear these days to embrace data-driven decision making as a standard operating procedure from a cultural and technological perspective, educational big data is not yet widely spread (Jülicher, 2018). The leap from a 'small data set' of canonical student records such as student's courses, modules, and grades, to the 'big data set' of detailed student activity, that ranges from virtual learning environments (VLEs) and interactions with library systems to self-declared data via student apps, represents a growing concern for those who would like to integrate data for learning analytics.

This situation impacts the rate of adoption and expansion of learning analytics (LA), a technology and practice also known as the third wave, which is seen today as the metacognitive component that allows individuals and institutions to understand learning and make informed decisions about resource allocations and required interventions to promote learner success (Brown, 2011). It further justifies the fact that the number of HE institutions engaged in not only "de-siloing" the students' "static data" (student records) but also in capturing their "fluid data"3 (traces of student interaction with university's space, systems and services) is still quite limited.

These implications contradict the 2011 Horizon Report predictions (Johnson et al., 2012, p. 28) about learning analytics' widespread adoption before the end of the decade, as there seem to be significant challenges standing in the way of realizing this change, despite the fact that the industry categorizations based on levels of intangible assets and competitive intelligence activity (Erickson; Rothberg, 2013) suggest that big data would be a good fit for education.

Nevertheless, the adoption of this new learner-centred service ethos is seen by many experts as necessary to develop more personalized systems and more effective and immersive learning experiences based on a continuous monitoring that supports curricular and co-curricular diagnostic, formative, and summative assessment (De-Freitas et al., 2015; Redecker et al., 2011).

\subsection{The academic library new narrative for communicating value}

The need for a comprehensive metaframe of learning and knowledge is currently reshaping university to attune it to student expectations for a more personalised learning experience by harnessing newly emerging learning enabling and student success technologies (World University Consortium, 2014). Within this context, academic libraries are facing new challenges and opportunities. As a result of the Bologna Process, the European Higher Education Area (EHEA) framework mandates, and technological developments, university libraries have begun to play a more active role in the changing educational system (Repanovici; Landøy, 2010). The "multiplicity of roles" previously not related to the academic library's traditional mission (Murray, 2014), the redesign of library spaces, the emergence of new librarian profiles, the development of partnerships between the library and faculty, and the progression from the passive liaison model to the proactive consulting one have repositioned the library at the pedagogic debate table and impacted on the librarian's role in a fundamental way (Wawrzaszek et al., 2008; Frank; Howell, 2003; Donham; Green, 2004; Dodd, 2007). 
They have also contributed to the debate of disciplinary identity, as well as the proliferation of terms such as "hybrid librarians", "blended professionals" or "third space professionals" according to Whitchurch's hierarchy (2008), to flag the boundary-spanning nature of academic library work today. These changes have engaged librarians in the development of an extended skill set to cover other related domains (Corrall, 2010), the exploration of what students need to know and which resources are the most appropriate (Dodd, 2007) and the pursuit of partnerships with the academic community in an overarching goal to help the millennium generation's identity, cognitive, and psychological development.

Attuned to the dynamics of a new environment where library professionals and academic domains are reweaven "into a new professional identity" (Long, 2016, p. 253), professional bodies are starting to consolidate guidelines around the reinvention and enhancement of library spaces and practices, and especially those related to current metrics and library data reports. In response to the changing context, the Association of College and Research Libraries (ACRL) has also narrowed the emphasis of the academic library value focusing on the library's impact on "institutional priorities for improved student learning and success" (Oakleaf; Kyrillidou, 2016, p. 758), while librarians and administrators are starting to view the use of learning analytics as a promising tool for illustrating ways that academic libraries contribute to institutional productivity and academic achievement (Jones; Salo, 2018).

Under the enduring effects of the grim economic climate of the last decade and the inefficiency of current practices, namely library use data collection through random sampling or ad hoc surveys, to reaffirm the place of academic libraries as learning spaces (Sinclair, 2009), the international community has begun to realise what a positive impact a change in the metrics of library success (Spiro; Henry, 2010; Oakleaf; Kyrillidou, 2016; Stoffle et al., 1996), including regular data collection and analysis and constant monitoring and assessment, might have on the demonstration of library services' value to users (value-as-results or value-in-use) (Saracevic; Kantor, 1997) and strategic planning successful outcomes.

The creation of a new narrative for communicating academic library's role and unique contribution to the university's strategic agenda (Jantti, 2014) has therefore become an imperative for the international LIS community in order to excel in challenging times and better cater for the future. This turn is marked by the experimentation with a variety of tools and methods to collect and capitalize on the library use data overtime, ranging from changes to official annual library statistics such as the ones conducted by the Association of Research Libraries (ARL) and the Council of Australian University Librarians (CAUL) (Kyrillidou, 2000; Jilovsky, 2006), to collection assessment methods beyond ROI and involvement in learning analytics. Seen the collection of data about the physical library activities as an additional form of library "living intellectual capital" that can be both input and output of organizational activity (Snyder; Pierce, 2002) and that needs to be identified, measured, and at the end of the day evaluated (Gallego; Rodríguez, 2005), Manchester Metropolitan, Leeds Metropolitan, Huddersfield, Roehampton, Cornell, and Michigan State Universities, as well as the Universities of Wollongong and Wyoming are among institutions that have been recently taking steps to analyze a huge variety of data that includes library usage, in addition to attendance, to determine student engagement and anticipate retention (Allison, 2015). At the same time, there is a growing interest in research on the academic libraries' appetite for analytics (Jisc LAMP 4 , LIILA ${ }^{5}$, CLLASS $^{6}$ projects), that facilitates the professional discourse in the field, and investigates correlations between the patron use of the library (workshops, reference service, space/equipment/material use, etc.) and student success.

Although the field is experiencing an abundance of publications since, 2008 on the increasing international activity aiming the exploration of the relationship between undergraduate academic disciplines and library use (Bridges, 2008), the investigation of reasons impacting library use data collection and their integration's prospects in campus-wide student success support systems, and finally the exploitation and maximization of the many possible uses for library and institutional data through the development of innovative solutions, little is known about the way the Greek academic library community, especially the high managerial agents, look upon these new developments.

\section{Research scope, objectives and methodology}

The researchers' intention was to provide a two-faceted Straussian grounded theory approach that would add breadth, complexity and depth to the topic by entering the world of participants from their perspective to make discoveries that would contribute to the development of empirical knowledge and help generate theory for an area where little information is available (Corbin; Strauss, 2008). Before addressing Greek academic library directors with a set of interview questions inquiring whether active involvement in LLA (Library data integration in Learning Analytics) projects is seen as a real opportunity for libraries to both take a strategic lead on campus in the data and analytics area and develop new or improved services for the enhancement of student experiences and the discovery of connections between their contributions and institutional outcomes, the authors elicited the opinion of two prominent international LA technology experts around the library's potential and implications associated with connecting its data to campus LA systems.

For the purposes of the inquiry, the researchers pursued where necessary an analysis of international trends and challenges, although the primary focus of the study was on the Greek academic library context. More specifically, the collection of first-hand knowledge of the way the international learning analytics setting is currently addressing the topic of in-student activity data integration within broader campus information systems was framed within the researchers' intention to contribute to the pluralistic, multi-perspectival dynamics of this study, as the experts' experience-derived 
technology-oriented perspective would help avoid potential monological or monodisciplinary pitfalls by informing the analysis of the second set of interviews (library directors' interview findings) with most current LA specialists' insights.

The second leg of the research aimed to initiate a discussion with a purposive sample of university library leaders in an overarching goal to identify tensions between current and potential new practices that could extend the community's understanding of reasons impacting the systematization of the collection of in-library user activity data for the Greek higher education context. It also envisioned contributing to the knowledge base of critical library adjustments necessary to truly, adequately, and effectively support the learning and teaching process.

The library directors' email interviews conducted in the participants' native language (Greek) were deployed around the desk research derived dimensions (Sclater's taxonomy ${ }^{7}$ ) of infrastructure, skills, partnerships, resources, ethical considerations, privacy, and organizational culture. During the design of the open-ended questionnaire, we chose to paraphrase many LLA related concepts as the LA terminology is not widely spread in academic Library and Information Science (LIS) environments yet. According to Drachsler and Greller (2012) the term "learning analytics" is still rather vague, a shared practice in the area is only just emerging, and a scientifically agreed definition is lacking. The name of the domain itself carries a highly subjective interpretation, which might have also influenced to some extent the answers in the survey.

In a nutshell, the chosen expert elicitation research design was deemed to be especially useful during this exploratory phase as it can better highlight areas marked by the lack of empirical evidence. Site triangulation, that is the effort to reduce likelihood that participants would be influenced by their higher education institutions' culture or dynamics (Shenton, 2004) and the explanation of the study's boundaries and the extent to which the findings may be true in other settings were among measures taken to enhance the trustworthiness and credibility of our study that could potentially be criticised for its small participant sample size.

\section{Findings}

\subsection{International learning analytics expert opinion}

According to LA experts' responses $^{8}$ to our web-based open-ended survey (Appendix Questionnaire A), library data integration in learning analytics systems "is feasible but requires substantial investment in technology, the provision of ethical principles to handle the information and institutional adoption of this new philosophy". When asked about data collection granularity (Q.4), they argued that

"It depends on its use and should be decided based on the potential for concrete advantages to improve the student experience. Interconnected data sources have more power than isolated population measures. Data interpretation in learning experiences is highly dependent on the context".

Moreover, Pedro-José Muñoz-Merino, assistant professor at the Department of Telematic Engineering of the University Carlos III of Madrid, Spain, stressed the need to allow the user to...

"...select if his/her information should be identifiable or not. In order to take more advantage of the approach, I think the in-library data should be connected with data from other initiatives to infer better intelligent information..."

Both interviewees posited that the question of the librarians' ability to effectively cope with the implications and requirements of innovation, including their involvement in learning analytics interventions $(Q .5)$, is dependent on institutional support:

"It depends on the support given at the institutional level. I can see the two extremes of this trade-off. A library with comprehensive support to deploy such innovation, and others that have no additional resources and therefore will remain with their conventional operations."

"... academic librarians are capable to make this change, but I think additional financial resources are necessary. For example, they would need to invest more time or having more people working on it, or I think they would need some training on this topic."

When asked whether they believe students would welcome shared library-faculty learning analytics interventions (Q.7), their answers were conditionally affirmative, as they expressed the opinion that students' buy-in depends on the administrators' capability to provide evidence that...

"...there is a clear and unequivocal connection with improvements on their learning experience. Otherwise, there is a high risk of being perceived as arbitrary data gathering (at best), or student surveillance (at worst). Students need to be not only aware but understand these benefits or improvements."

Finally, it was argued that the ethical considerations of the LLA (Library data integration in Learning Analytics) initiatives (Q.8) are not too different from the concerns related to any other data used for learning analytics. 


\subsection{The Greek academic library directors' perspective}

The second set of interviews (Appendix Questionnaire B), aiming to elicit the library expert opinion on the topic in an effort to contribute to baseline knowledge on the organizational context and interplay of forces that hinder or facilitate library data collection and capitalization, was conducted in November, 2017.
Expert opinion on the organizational context and interplay of forces offers a conceptual model of factors inhibiting or supporting library data integration in university information systems

All three public university library directors that were invited to participate in the email interview agreed on the insufficiency of currently collected library use data (Q.1), acknowledging the fact that

"...there is neither a [library use data] systematic collection nor their in-depth evaluation."

"...it takes more than making them available in a simple, explicit, comprehensible and meaningful way; the most important thing is to be capitalized by recipients, that is teaching personnel. Therefore, communication and utilization are two interconnected and indispensable aspects [in that respect]."

With regard to the feasibility of systematizing the collection of student in-library data for the benefit of learning analytics' campus-wide initiatives (Q.2), Professor Zachos, head librarian at the University of loannina, Greece, noted that there is still room for improvement in the data recording process. Overall, interviewees argued that although systematic data collection is a painstaking procedure

"...nevertheless it is not unfeasible. It initially requires the [re]organization of library operations, consistency and firmness in keeping up procedures so as to have reliable outcomes."

As to their opinion on the level to which in-library user activity data should be better collected and analyzed (Q.3), Professor Zachos posits that

"In order for a personally identifiable data collection to take place, there should be a link-up between the library and student performance evaluation process. To this day, there is no such association. Therefore, what could be [provisionally] done is to offer an overview of library use through an aggregated data presentation. As yet there is no such development. Provided there is [strategic] forethought, related procedures can be chosen with most appropriate that of on-line recording".

In the words of a different respondent (See note 8):

"Library service use data collection granularity depends on the type of service [offered]. For instance, we keep track of our website traffic, not knowing however how many of our website visitors are faculty, students or other user groups. On the other hand, circulation can be configured so as to statistically inform on user variables. Therefore, depending on our expectations, we can modify the way we gather statistics which usually are anonymous user group aggregations".

When asked about the librarian ability to effectively cope with the implications and requirements of such innovation as well as their involvement in learning analytics interventions (Q.4), one of the library directors expressed the opinion that:

"The older librarian generation will most probably not [ be in the position to cope with the LLA development requirements], while the New Information Professionals should."

The need for an active involvement of professional associations in the process was reiterated several times.

"...it [librarian involvement in LLA projects] requires, as it goes with every new process, certain professional development actions. Furthermore, I believe that it will all have much better results provided decisions are taken by a higher collective body as on many occasions a collectivity decision implementation can be supportive (e.g. HEALLink-Hellenic Academic Libraries Link)."

With regard to the academic library readiness to move on to the new paradigm (Q.5), Professor Zachos argues that it is not as much a question of resources as it is of political will and interest from the faculty side. Reference was also made to the equally effective strategy of pursuing participation of high ranked library administration in the process (including library committee or deanery). As to the possibility of students welcoming a library/faculty collaboration (Q.6), their responses reflect their uniformity of opinion around difficulties to get student buy-in:

"Rather negatively. Library is considered a reading room by quite a lot of students. In order to encourage student buy-in, there should be involved an academic department topic-related decision."

"As it is always done: through pilot testing in collaboration with some innovative teachers and as soon as results are available there will be more stakeholders convinced."

"It would neither be easy, nor immediate. It requires a lot of time and communications (organizing events, distributing print material, regular updates etc.). It would also take concrete evidence and gradual integration into library processes (e.g. subject guides requests that lead to new acquisitions)." 
Their answers to the question of how much prospect they see in HE administrators supporting the integration of library use data in LA systems (Q.7) signal a diffuse scepticism:

"Given the fact that Universities lack financial and HR resources, they would be reluctant in my opinion, unless it had to do with implementation as part of a wider project involving all related Higher Education institutions and their libraries called to use the application (during or after) and to contribute the required data. It comes without saying that all these new ideas and practices need staff training beforehand and perhaps special equipment, material and software (whether on-premise or cloud based)."

"Promising but difficult to implement. Hellenic University administrations despite talks around supporting their libraries, in practice have given little room to the educational dimension of the library with only a few exceptions. The endeavor calls for collective action, training and perseverance."

Finally, our interview participants did not believe there will be any privacy/ethical issues so long as LLA interventions are based on non-identifiable user data (Q.8).

\section{Discussion}

Currently, library science research around the globe has pivoted to focus on the impact of library services (Kawalec, 2017), the relationship between library services and grades, retention, and achievement, marking a "significant turn" in assessment and evaluation as a response to contemporary pressures on HE institutions. However, despite the proliferation of international research on the relation of library use to student success, the analysis of our findings reveals that the Greek academic library community is not as yet considering moving beyond traditional measures and methodologies that no longer reflect the spectrum of purposes fulfilled by libraries today (Weiner, 2005).

Although Greek library professionals recognise the value of systematically collecting data from several different service points for planning and decision making, service personalization, increasing library visibility, productivity and effectiveness, they acknowledge that this has not as yet done neither consistently nor effectively. Therefore, while the current educational environment is offering librarians the opportunity to accelerate change (Rader, 2004), update their role in the context of the institutional mission, and see the systematic collection and sharing of library data, including LLA initiatives (Library data integration in Learning Analytics), as a reform that envisions making the educational process more effective, functional, and productive, Greek library administrations are not yet considering the implementation of interventions that would link their work to institutional data as they feel that existing data capability issues undermine their effort to prove that library's contributions lead to improvements in learning.

Besides the fact that analytics is a tool under development and part of an emerging field that will likely evolve dramaticaIly in the near future (Mattingly et al., 2012), their reluctance to embrace this transformational change that would help libraries to maintain their viability and to develop an even higher profile within the context of institutional missions and outcomes, is attributed by interviewees to a number of reasons among which:

- the lack of financial support and human resources capable to coping with their new roles and mandates;

- the absence of a systematic data collection process and in-depth evaluation of available library use data;

- the lack of strategic forethought, political will and interest from the faculty side;

- the existing institutional culture that leaves little room to the deployment of the educational dimension of the library.

Greek public universities belong to the category of "limited users" of advising technology as compared to their north European counterparts that are increasingly seeing themselves as successful in the advising realm and report rising levels of collaboration (Tsai et al., 2018). Furthermore, Greece is one of the six "systems in danger" as funding decreased while student numbers grew between 2008-2015, also ranking low (35 th place) in terms of university independence, exhibiting a high inefficiency in terms of allocation of human and financial resources and, most importantly, a high state dependence in decisions regarding students and faculty selection, funding, and organizational matters (Pruvot et al., 2017; European University Association, 2016; Mylonas, 2017). Although, several national and European community support framework funds during the past decade gave Greek libraries the opportunity to put forward extensive infrastructural, human resources development and interlibrary collaboration projects, library data collection is still limited in scope while only a small percentage are being used for the development of added value services (Strakantouna, 2005).

Despite operating in this over-regulated, micro-managed, heavily restricted environment in terms of financial, staff and admissions' autonomy (Estermann et al., 2011), Greek public academic librarians also suffering the effects of severe staff and expenditure reductions under the Big Recession effect (Giannakopoulos et al., 2014; Simón-Martín et al., 2016) may generally score high in knowledge acquisition and sharing on an individual level. However, according to Koloniari and Fassoulis' research findings (2017) their libraries are not characterized as knowledge-intensive innovation-oriented organizations as there are limited organizational knowledge management application opportunities, their efforts remain focused on managing explicit knowledge and the transition from knowledge acquisition to diffusion and full integration still seems a vague aspiration. Therefore, within this context it is only natural for library directors' to express strong concerns associated with funding, inflexible organizational structures, and culture.

Their hesitation to embrace IT-driven transformational changes that would strengthen the library's position in the edu- 
cational process, according to our findings could also stem from the ineffective communication with other institutional units, including faculty, which means that library professionals are left rather alone to craft the future of their profession (Long, 2016). This fact makes even more urgent the need to rethink ways to involve staff in meaningful communication, reflection, and growth with an eye on new trends as

cultural incongruence often leads to differences in perspectives, goals, strategies within the organization thus inhibiting the organization's ability to perform at the highest levels of effectiveness (Cameron; Quinn, 2006).

Furthermore, the lack of a clear understanding of how academic library professionals can link up library data to student performance evaluation data makes it rather improbable for the local context to be soon able to put in place new measures.

Although the attempt to transfer corporate management theories to universities may occasionally offend the collegial culture, a culture that rewards conformism and centralization to the detriment of innovation, initiatives and team work (Kyrillidou, 1997) and face profound scepticism or even hostility (Bergquist; Pawlak, 2008), respondents demonstrated their vivid interest in LLA initiatives not only by outlining challenges but also by proposing ways to remedy the situation and prepare the community before these new perspectives. They stressed the necessity to take proactive rather than defensive approaches to demonstrate the library value and contributions to the learning and teaching process, seek out continuing professional development opportunities, institutional support and a clear set of first-instance evidence to support their case and get the community buy-in.

Discussions about library's position in the learning analytics realm are rare in the local context (Sant-Geronikolou, 2018b). Nevertheless, the library directors' remarks were perfectly attuned with the learning analytics experts' interview findings on the operationalization measures necessary to streamline library data integration in learning analytics and technology-driven student success support initiatives. This fact further suggests that decision makers, aware of the higher education emerging scenarios and the changing purposes that academic libraries fulfil today, are gradually expanding their focus to exploring new methods and processes that would prepare for engaging in a new generation of personalized learning environments while balancing faculty, student expectations, privacy and the institutions' philosophy of student development.

Expressing their confidence in the adequacy of the new information professionals' skills to cope with the present job requirements, they argued on the necessity to approach the continuing professional development topic in a systematic and proactive way especially for the older librarian generations who had received an uneven and, in some cases, greatly lacking professional preparation. It is a fact that until recently and before systematic action to transform the field into a uniform area of information science, local LIS study programs had been mere collection codes with high degree of insulation and little compliance with the changing workplace scenarios (Sant-Geronikolou, 2018a; Moniarou-Papakonstantinou; Tsatsaroni, 2008).

Library directors greatly concerned with community buy-in, seem to be sharing a lot of the considerations of their North American counterparts, as recorded in the Spec Kit 360 American Research Libraries' survey (Perry et al., 2018), especially in relation to the lack of institutional support, ambiguity surrounding campus needs and uses for library data and repeatedly argued on the need to

- offer flexible customizable solutions;

- involve professional associations in the process;

- closely collaborate with innovative forward-looking faculty;

- mobilize academic departments and pursue the implementation of a wider project across multiple institutions and their corresponding libraries;

- invest time and effort to gathering and communicating concrete evidence in support of library data association with student success and retention;

- engage in collective action and skills' development activities.

According to their comments, strategic forethought including collective action, training and communications are crucial to the success of any LLA system. To assure stakeholder buy-in, the processing of library use data should be seen as a collaborative co-creation endeavor beyond organizational boundaries and narrow disciplinary perspectives in order to match the users' reasonable expectations of how their data will be used and mitigate the skepticism surrounding student co-curricular activity measurements. As to the priority steps that would best address the Greek context at this point, they uniformly insisted on the urgency of putting together campus-wide student support coordination committees, and delivering targeted communication activities especially concentrating on the dimensions, implications and prospects of library involvement in learning analytics projects, as

"academic libraries have now reached the stage where immediate decisions and groundbreaking actions are required". 
Finally, given the current library operations' scenario, respondents elt that the systematc tracking and sharing of in-library student activity can at this point only go through aggregated or voluntary anonymized pipelines without however expressing any further concerns with regard to the ethical and privacy LLA implications. This can be potentially attributed to the fact that students become increasingly accustomed to the personalized and data-driven experiences of both digital and physical environments. It could also be stemming from the conviction that the newly introduced changes by academic libraries pursuant to the new EU Regulation 2016/679 of the European Parliament on the protection of natural persons with regard to the collection and processing of personal data (GDPR) will help safeguard the interests of all parties involved in LLA projects, as libraries gradually transform to academic commons (Holmgren; Spencer, 2014) and higher education progresses closer to the intelligent campus scenario (Van-Trigt, 2016).

The extent of participants' concerns over a wide range of aspects, including but not limited to the higher education data collection grey areas, the centralized character of a system still unable to timely address pedagogical and technological developments, the persistence of top-down approaches when streamlining changes, uncoordinated communication and collaboration between intra-institutional units, suggest: (1) the reconsideration of the feasibility and applicability of LLA interventions for the Greek higher education context, and (2) the exploration of and experimentation with alternative hybrid or middle way solutions that could better address the current scenario.

\section{Study limitations}

The limitations involved with this exploratory study are not very much different from the validity and generalizability issues inherent in any qualitative research. The identification of connections among the interviewees' viewpoints was considered to be the researchers' best alternative to generalizability (Lincoln; Guba, 1985) and representativeness, as the believe that when participants describe similar experiences their stories and reflections acquire more power. However, we have to stress that the survey conducted is only exploratory and therefore no far-reaching conclusions should be drawn about the library profession in the Greek higher education context. Additionally, since the data are based on nonrandom samples, the results are not projectable to any population other than participants expressing their points of view in these samples.

Additionally, taking into account the fact that as our research was conducted in the midst of severe economic downturn with implications for the library world that was impossible to capture in a single study, inevitably current phenomenographic research, which is a snapshot set in a specific time and under specific circumstances, can only be considered a single step in a larger exploration. Nevertheless, this work will hopefully pave significant areas for future investigation aiming to raise questions and helping better appreciate some of the context specific complexities that are involved.

\section{Value and significance of the study}

So far there has been an abundance of country-specific studies on user perceptions of service quality and librarian skills. However, we did not identify any study for the specific context of Greek libraries that examines the academic librarian's perceptions of potential inhibiting factors to the library dynamic involvement in the learning and teaching process through integration of library data in learning analytics initiatives.

Despite the small number of respondents, we consider that there was an adequate representation because the content of the answers was substantially detailed. Interpretation of the results sought to support its general meaning by making connections to other analyzed sources, such as those gathered in the literature review and the LA experts' interview comments as recommended by Connaway and Powell (2010). This way, the chosen methodology adds reliability to the study, because it results from the interconnections made between multiple sources, which are set up against each other to interact and shed light on the starting points. The greatest merit of this work nevertheless resides in the overarching discussion that these findings generate.

\section{Conclusions and future lines of research}

As library staff is becoming more heterogeneous and multi-disciplinary, since the number of professionals entering the field from other domains of knowledge keeps rising and collaborations, convergence, partnerships, and new enhanced services are continuously added to the academic library routines, the need for addressing LIS research topic in multi-faceted and multi-dimensional ways becomes even more pressing.

In this realm, the data gathered between December 2016-2017 have been targeting the investigation of both academic library climate and operations, bringing to light information on the perceptions of library directors and LA experts around the capitalization of student in-library workflow data within learning analytics systems. During the analysis of the findings, we also had the opportunity to explore new and old theoretical perspectives that could support stakeholder buy-in, with an overarching goal to offer a conceptual model of factors that are conducive or supportive to the library integration in learning analytics initiatives, thus facilitating the formulation of context specific recommendations. 
The participants' perspective provided information to help the community appreciate the Greek higher education organizational culture and assess the feasibility and applicability prospects of future local LLA interventions, thus guiding the design of shared analytics projects by adding actionable data to the user requirements' knowledge base for future reference. It has also provided inspiration on how to kickstart the LLA conversation at the upper-managerial division and on how to accelerate top-down initiatives as the highly hierarchical and centralized ecosystem leaves little room to bottom-up innovation. Moreover, it has highlighted a number of grey areas where HE data capabilities and departmental units' collaboration is concerned which could become topic of further research. It has also opened for discussion the topic of professional associations and library schools' involvement in supporting and advocating for the enhancement of library data capabilities.

According to the experts' insightful comments, it is of crucial importance to understand this development as part of a larger process. Before deploying any systematic library data collection solutions, it must therefore be ensured that a) the organizational culture is prepared with policies and skills necessary to successfully distill actionable intelligence from their use and b) clear information on reasons and ways of library use data collection is provided.

Our results could be interpreted in the direction that LA experts are moderately optimistic about library data integration in shared analytics systems, while librarians are willing to discuss new solutions and to renegotiate their traditional positions related to the enhancement and capitalization of library use data. What our findings indicate and which is also corroborated in previous studies is that faculty do not perceive librarians as valued collaborators in student learning, meaning that librarians are left rather alone to craft the future of their profession.

The role of faculty and professional associations can be therefore critical in ensuring that barriers and mistrust are mitigated. We believe that the idea of involving all stakeholder groups through training and communications around the impact that these developments may have on the community holds great potential for strengthening LLA buy-in from the different stakeholders as it will not be possible for librarians to

a) make sense of the enormous data volume generated without having a priori been adequately informed of and educated on the potential impact and benefits of their active involvement in campus-wide LA initiatives;

b) get target population buy-in without specialized instruction.

Faculty and student involvement will be one of the keys to wider user acceptance, as it is required if LA tools are to serve the intended objective of improving the educational process. Another crucial step could be to see LLA as a knowledge management (KM) project whose success could be jeopardized for the same reasons as any other project among which the lack of clear KM vision and strategy, negative attitudes towards knowledge sharing and absence of continuous top management support. Above all, organizations should come in terms with an organizational knowledge sharing culture and cross-fertilization of ideas originating from outside the field of librarianship.

\section{Notes}

1. Yerevan Communiqué 2015.

http://www.enqa.eu/wp-content/uploads/2015/06/Yerevan-Communique.pdf

2. Kuh (2009, p. 683) has defined student engagement as

"the time and effort students devote to activities that are empirically linked to desired outcomes of college and what institutions do to induce students to participate in these activities."

3. In the "Bricks to clicks" report (Shacklock, 2016), the HE Commission, UK, draws a distinction between what we call 'static data' and 'fluid data'. Static data is data which is collected, recorded and stored by institutions and traditionally includes student records, staff data, financial data and estates data. Fluid data is the data that is generated through the increasingly digital way a student interacts with their university, such as swipe card data from access-controlled campus buildings, log-ins to the virtual learning environment (VLE) and e-books or online journal downloads.

4. Library Analytics and Metrics Project. https://www.jisc.ac.uk/rd/projects/library-analytics-and-metrics-project

5. Library integration into institutional learning analytics, Institute of Museum and Library Services (IMLS), National Leadership Grants for Libraries, 2017.

https://www.im/s.gov/sites/default/files/grants/lg-98-17-0019-17/proposals/lg-98-17-0019-17-full-proposal-documents.pdf

6. Connecting libraries and learning analytics for student success, Institute of Museum and Library Services (IMLS), National Leadership Grants for Libraries, 2018.

7. A taxonomy of ethical, legal and logistical issues of learning analytics v.1.0, Niall Sclater, March 2015.

https://analytics.jiscinvolve.org/wp/2015/03/03/a-taxonomy-of-ethical-legal-and-logistical-issues-of-learning-analytics-v1-0 
8. About the canvassing of experts: many of the participants in our research elected to remain anonymous. Complete sets of for-credit and anonymous responses can be made available upon request.

\section{References}

Allison, DeeAnn (2015). "Measuring the academic impact of libraries". Portal: Libraries and the academy, v. 15, n. 1, pp. $29-40$. https://doi.org/10.1353/pla.2015.0001

Bergquist, Willian H.; Pawlak, Kenneth (2008). Engaging the six cultures of the academy: Revised and expanded edition of the four cultures of the academy. John Wiley \& Sons. ISBN: 9780787995195

Bridges, Laurie M. (2008). "Who is not using the library? A comparison of undergraduate academic disciplines and library use". Portal: Libraries and the academy, v. 8, n. 2, pp. 187-196.

https://www.learntechlib.org/p/71269

Brooks, Christopher; Thayer, Terri-Lynn (2016). Institutional analytics in higher education. Research report. Louisville, CO: Educause Center for Analysis and Research (ECAR).

https://library.educause.edu/resources/2016/2/institutional-analytics-in-higher-education

Brown, Malcolm (2011). "Learning analytics: The coming third wave”. Educause learning initiative brief, v. 1, n. 4, pp. 1-4. https://library.educause.edu/resources/2011/4/learning-analytics-the-coming-third-wave

Cameron, Kim S.; Quinn, Robert E. (2006). Diagnosing and changing organizational culture. Based on the competing values framework. Jossey-Bass, San Francisco, CA.

https://bit.ly/2Mlyltf

Chen, Hsin-liang; Doty, Philip; Mollman, Carol; Niu, Xi; Yu, Jen-Chien; Zhang, Tao (2015). "Library assessment and data analytics in the big data era: Practice and policies". In: Proceedings of the $78^{\text {th }}$ ASIS\&T Annual meeting: Information science with impact: research in and for the community, Association for Information Science and Technology, v. 52, n. 1, pp. 1-4. https://doi.org/10.1002/pra2.2015.14505201002

Connaway, Lynn-Silipigni; Powell, Ronald R. (2010). Basic research methods for librarians. Westport: ABC-CLIO. ISBN: 1591588650

Corbin, Juliet; Strauss, Anselm (2008). Basics of qualitative research: Techniques and procedures for developing grounded theory ( ${ }^{\text {rd }}$ ed.). Thousand Oaks, CA: Sage. ISBN: 9781412906449

Cormack, Andrew-Nicholas (2016). "A data protection framework for learning analytics". Journal of learning analytics, v. 3, n. 1, pp. 91-106.

https://doi.org/10.18608/jla.2016.31.6

Corrall, Sheila (2010). "Educating the academic librarian as a blended professional: a review and case study". Library management, v. 31, n. 8/9, pp. 567-593.

https://doi.org/10.1108/01435121011093360

Cox, Brian L.; Jantti, Margie H. (2012). "Discovering the impact of library use and student performance". Educause review, n. July 18, pp. 1-9.

https://ro.uow.edu.au/cgi/viewcontent.cgi?article=1507\&context=asdpapers

De-Freitas, Sara; Gibson, David; Du-Plessis, Coert; Halloran, Pat; Williams, Ed; Ambrose, Matt; Dunwell, lan; Arnab, Sylvester (2015). "Foundations of dynamic learning analytics: Using university student data to increase retention". British journal of educational technology, v. 46, n. 6, pp. 1175-1188.

https://doi.org/10.1111/bjet.12212

Dodd, Lorna (2007). "The future of librarianship: moving out of the library and into the faculty. How problem-based learning is transforming the traditional role". Sconul focus, n. 41, pp. 4-8.

https://www.sconul.ac.uk/sites/default/files/documents/Focus41.pdf

Donham, Jean; Green, Corey Williams (2004). "Perspectives on... developing a culture of collaboration: librarian as consultant". The journal of academic librarianship, v. 30, n. 4, pp. 314-321.

https://doi.org/10.1016/j.acalib.2004.04.005

Drachsler, Hendrik; Greller, Wolfgang (2012). "The pulse of learning analytics understandings and expectations from the stakeholders". In: Proceedings of the $2^{\text {nd }}$ intl conf on learning analytics and knowledge, pp. 120-129. ACM.

https://doi.org/10.1145/2330601.2330634

Erickson, G. Scott; Rothberg, Helen N. (2013). "A strategic approach to knowledge development and protection". The service industries journal, v. 33, n. 13-14, pp. 1402-1416.

https://doi.org/10.1080/02642069.2013.815740 
Estermann, Thomas; Nokkala, Terhi; Steinel, Monika (2011). “University autonomy in Europe II. The scorecard”. BrusseIs: European University Association.

http://agir-ups.info/wp-content/uploads/2013/01/University_Autonomy_in_Europe_II_-_The_Scorecard.sflb_.pdf

European University Association (2016). "Public Funding Observatory Report 2016".

https://eua.eu/resources/publications/717:eua-public-funding-observatory-2016.html

Farkas, Meredith G. (2012). "Participatory technologies, pedagogy 2.0 and information literacy". Library hi tech, v. 30, n. 1, pp. 82-94.

https://doi.org/10.1108/07378831211213229

Frank, Donald G.; Howell, Elizabeth (2003). "New relationships in academe: Ppportunities for vitality and relevance". College and research libraries news, v. 64, n. 1, pp. 24-27.

Gallego, Isabel; Rodríguez, Luis (2005). "Situation of intangible assets in Spanish firms: an empirical analysis". Journal of intellectual capital, v. 6, n. 1, pp. 105-126.

https://doi.org/10.1108/14691930510574690

Giannakopoulos, Georgios; Koulouris, Alexandros; Kokkinos, Dionysis (2014). “Libraries in crisis: A glimpse over Greece and Cyprus". Procedia-social and behavioral sciences, v. 147, pp. 411-417.

https://doi.org/10.1016/j.sbspro.2014.07.121

Gregory, Mary-Sarah-Jane; Lodge, Jason-Michael (2015). “Academic workload: the silent barrier to the implementation of technology-enhanced learning strategies in higher education". Distance education, v. 36, n. 2, pp. 210-230. https://doi.org/10.1080/01587919.2015.1055056

Holmgren, Richard; Spencer, Gene (2014). The changing landscape of library and information services: What presidents, provosts, and finance officers need to know. White paper, Council on Library and Information Resources (CLIR). https://www.clir.org/wp-content/uploads/sites/6/2016/09/pub162.pdf

Jantti, Margie H. (2014). "Aspiring to excellence: maximising data to sustain, shift and reshape a library for the future". In: Proceedings of library assessment conferenc: Building effective, sustainable, practical assessment. Eds: Sarah Durso, Steve Hiller, Martha Kyrillidou, and Angela Pappalardo, pp. 15-22. Washington, DC: Association of Research Libraries. http://old.libraryassessment.org/bm doc/proceedings-lac-2014.pdf

Jilovsky, Cathie D. (2006). "Library statistics: reflecting yesterday, today and tomorrow". In: Proceedings of the $6^{\text {th }}$ Northumbria conf on performance measures for libraries and information services, Durham, United Kingdom. https://www.researchgate.net/publication/242376216_Library_Statistics_reflecting_yesterday_today_and_tomorrow

Johnson, Larry; Smith, Rachel; Willis, Holly; Levine, Alan; Haywood, Keene (2012). NMC Horizon Report: 2011 edition. The New Media Consortium.

Jones, Kyle M. L.; Salo, Dorothea (2018). "Learning analytics and the academic library: Professional ethics commitments at a crossroads". College \& research libraries, v. 79, n. 3, pp. 304-323.

https://doi.org/10.5860/crl.79.3.304

Jülicher, Tim (2018). "Education 2.0: Learning analytics, educational data mining and Co". In: Hoeren, T.; Kolany-Raiser, B. (eds.) Big data in context. Springer briefs in law, Springer.

https://link.springer.com/content/pdf/10.1007/978-3-319-62461-7_6.pdf

Kawalec, Anna (2017). "Research trends in library and information science based on Spanish scientific publication 2000 to 2010 ". Malaysian journal of library \& information science, v. 18, n. 2, pp. 1-13.

https://mjlis.um.edu.my/article/view/1864

Kezar, Adrianna (2003). "Enhancing innovative partnerships: Creating a change model for academic and student affairs collaboration". Innovative higher education, v. 28, n. 2, pp. 137-156.

https://doi.org/10.1023/B:IHIE.0000006289.31227.25

Kincheloe, Joe L. (2005). "On to the next level: Continuing the conceptualization of the bricolage". Qualitative inquiry, v. 11, n. 3, pp. 323-350.

https://wolfworld.typepad.com/practicum/files/bricolage.pdf

https://doi.org/10.1177/1077800405275056

Koloniari, Maria; Fassoulis, Kostas (2017). "Knowledge management perceptions in academic libraries". The journal of academic librarianship, v. 43, n. 2, 135-142.

https://doi.org/10.1016/j.acalib.2016.11.006

Krause, Kerri-Lee D. (2011). “Chapter 6. Transforming the learning experience to engage students”. In: Thomas, L.; Tight, M. (eds.). Institutional transformation to engage a diverse student body. Bingley: Emerald, pp. 199-212. ISBN: 9780857249036 https://doi.org/10.1108/S1479-3628(2011)0000006020 
Kuh, George D. (2009). "What student affairs professionals need to know about student engagement". Journal of college student development, v. 50, n. 6, pp. 683-706.

https://doi.org/10.1353/csd.0.0099

Kyrillidou, Martha (1997). "The use of statistics by libraries in North America". In: $6^{\text {th }}$ Panhellenic academic libraries conference, Athens, Greece.

http://eprints.rclis.org/9814

Kyrillidou, Martha (2000). "Research library trends: ARL statistics". Journal of academic librarianship, v. 26, n. 6, pp. 427-437. https://doi.org/10.1016/S0099-1333(00)00177-4

Lincoln, Yvonna S.; Guba, Egon G. (1985). “Establishing trustworthiness". In: Naturalistic inquiry, pp. 289, 331. ISBN: 0803924313

Long, Dallas (2016). Librarians and student affairs professionals as collaborators for student learning and success. Doctoral dissertation. Department of Educational Administration and Foundations: Educational Administration, Illinois State University. http://doi.org/10.30707/ETD2016.Long.D

Mattingly, Karen D.; Rice, Margaret C.; Berge, Zane L. (2012). "Learning analytics as a tool for closing the assessment loop in higher education". Knowledge management \& e-learning: An international journal, v. 4, n. 3, pp. $236-247$. https://doi.org/10.34105/j.kmel.2012.04.020

Moniarou-Papaconstantinou, Valentini; Tsatsaroni, Anna (2008). "Library and information science education in Greece: Institutional changes and current issues". Education for information, v. 26, n. 2, pp. 85-100.

https://doi.org/10.3233/EFI-2008-26205

Murray, Adam L. (2014). The academic library and high-impact practices for student retention: Perspectives of library deans. Dissertation. The Faculty of the Educational Leadership, Western Kentucky University.

https://digitalcommons.wku.edu/cgi/viewcontent.cgi?article=1056\&context=diss

Mylonas, Paul (2017). Turning Greece into an Education hub. National Bank of Greece sectoral report: Higher education. https://www.nbg.gr/greek/the-group/press-office/e-spot/reports/Documents/Education.pdf

Oakleaf, Megan; Kyrillidou, Martha (2016). "Revisiting the academic library value research agenda: An opportunity to shape the future". Journal of academic librarianship, v. 42, n. 6, pp. 757-764.

https://doi.org/10.1016/j.acalib.2016.10.005

Perry, Michael R.; Briney, Kristian A.; Goben, Abigail; Asher, Andrew; Jones, Kyle M.; Robertshaw, M. Brooke; Salo, Dorothea (2018). Spec Kit 360: Learning analytics. Washington, DC: Association of Research Libraries, September 2018. https://doi.org/10.29242/spec.360

Picciano, Anthony G. (2012). "The evolution of big data and learning analytics in American higher education". Journal of asynchronous learning networks, v. 16, n. 3, pp. 9-20.

https://doi.org/10.24059/olj.v16i3.267

Pike, Gary R.; Kuh, George D. (2005). "A typology of student engagement for American colleges and universities". Research in higher education, v. 46, n. 2, pp. 185-209.

https://doi.org/10.1007/s11162-004-1599-0

Pruvot, Enora-Bennetot; Estermann, Thomas; Kupriyanova, Veronika (2017). Public funding observatory report 2017. European University Association, Brussels, Belgium.

https://www.eua.eu/downloads/publications/eua-pfo-report-december-2017.pdf

Rader, Hannelore B. (2004). "Building faculty-librarian partnerships to prepare students for information fluency: The time for sharing information expertise is now". College and research libraries news, v. 65, n. 2, pp. 74-77.

Redecker, Christine; Leis, Miriam; Leendertse, Matthijs; Punie, Yves; Gijsbers, Govert; Kirschner, Paul; Stoyanov, Slavi; Hoogveld, Bert (2011). The future of learning: Preparing for change. European Commission, Joint Research Centre, Institute for Prospective Technological Studies. Luxembourg: Publications Office of the European Union.

http://ftp.jrc.es/EURdoc/JRC66836.pdf

http://dx.doi.org/10.2791/64117

Repanovici, Angela; Landøy, Ane (2010). "Knowing the needs: A system for evaluating the University Library". In: Qualitative and quantitative methods in libraries conference, May 2009.

http://hdl.handle.net/1956/3705

Sant-Geronikolou, Stavroula (2018a). "South European undergraduate and continuing professional development program reconceptualization for the new information professional: a synergistic innovation perspective". Journal of integrated information management, v. 3, n. 1, pp. 24-29.

https://doi.org/10.18780/jiim.v3i1.4266 
Sant-Geronikolou, Stavroula (2018b). “Understanding in-library use data lifecycle within Greek and Spanish higher education ecosystems". Library hi tech news, v. 35, n. 7, pp. 13-17.

https://doi.org/10.1108/LHTN-10-2017-0077

Saracevic, Tefko; Kantor, Paul B. (1997). "Studying the value of library and information services. Part I. Establishing a theoretical framework". Journal of the American Society for Information Science, v. 48, n. 6, pp. 527-542.

https://doi.org/10.1002/(SICI)1097-4571(199706)48:6<527::AID-ASI6>3.0.CO;2-W

Scott, Cynthia-Luna (2015). The futures of learning 3: What kind of pedagogies for the $21^{\text {st }}$ century?. Unesco, Education research and foresight working papers.

https://unesdoc.unesco.org/ark:/48223/pf0000243126

http://hdl.handle.net/123456789/3747

Shacklock, Xanthe (2016). From bricks to clicks: The potential of data and analytics in higher education. London: Higher Education Commission.

https://cutt.ly/h7lU4i

Shenton, Andrew K. (2004). "Strategies for ensuring trustworthiness in qualitative research projects". Education for information, v. 22, n. 2, pp. 63-75.

https://doi.org/10.3233/EFI-2004-22201

Simón-Martín, José-Simón; Arias-Coello, Alicia; Simón-Blas, Clara (2016). “Impacto de la crisis económica en las bibliotecas universitarias españolas”. Revista española de documentación científica, v. 39, n. 3, e142.

https://doi.org/10.3989/redc.2016.3.1346

Sinclair, Bryan (2009). "The blended librarian in the learning commons: New skills for the blended library". College \& research libraries news, v. 70, n. 9, pp. 504-516.

https://doi.org/10.5860/crln.70.9.8250

Snyder, Herbert W.; Pierce, Jennifer-Burek (2002). "Intellectual capital". Annual review of information science and technology, v. 36, n. 1, pp. 467-500.

https://doi.org/10.1002/aris.1440360112

Spiro, Lisa; Henry, Geneva (2010). "Can a new research library be all-digital?. In: Council on Library and Information Resources". The idea of order: Transforming research collections for $21^{\text {st }}$ century scholarship, pp. 5-80.

https://www.clir.org/pubs/reports/pub147

Stoffle, Carla J.; Renaud, Robert; Veldof, Jerilyn R. (1996). “Choosing our futures”. College \& research libraries, v. 57, n. 3, pp. 213-225.

https://doi.org/10.5860/crl_57_03_213

Strakantouna, Vasilico (2005). “Epexeryasia prosopikon thethomenon kai prostasia tes ithiotikotetas sto sychrono perivallon ton vivliothekon kai eperesion pleroforeses" [Processing of personal data and protection of privacy in the modern library and information services environment]. Master's thesis, Ionian University, Information Science program.

http://dlib.ionio.gr/mtheses/strakantouna_privacy.pdf

Trowler, Paul; Wareham, Terry (2008). Tribes, territories, research and teaching enhancing the teaching-research nexus. Working paper. The Higher Education Academy, York.

https://cutt.ly/A7IOT5

Trowler, Vicki (2010). "Student engagement literature review". The Higher Education Academy, v. 11, n. 1, pp. 1-15. https://www.heacademy.ac.uk/system/files/studentengagement/iteraturereview_1.pdf

Tsai, Yi-Shan; Gašević, Dragan; Whitelock-Wainwright, Alexander; Muñoz-Merino, Pedro J.; Moreno-Marcos, P. Manuel; Fernández, Aarón-Rubio; Kloos, Carlos-Delgado; Scheffel, Maren; Jivet, loana; Drachsler, Hendrik; Tammets, Kairits; Calleja, Adolfo-Ruiz; Kollom, Kaire (2018). Sheila: Supporting higher education to intergrade learning analytics research report. https://sheilaproject.eu/wp-content/uploads/2018/11/SHEILA-research-report.pdf

Van-Trigt, Marjolein (2016). How data can improve the quality of higher education. SURF Net. https://hochschulforumdigitalisierung.de/sites/default/files/downloads/whitepaper-learning-analytics_en-def.pdf

Wawrzaszek, Susan V.; Wedaman, David G.; Turner, John W.; Aaron, Amira; Dembowitz, Lori (2008). “The old and the new c's". Pre-conference workshop presented at Nercomp annual conference, 2008, on the Future of the library, Brandels University.

http://bir.brandeis.edu/handle/10192/21941

Weiner, Sharon A. (2005). "Library quality and impact: Is there a relationship between new measures and traditional measures?". The journal of academic librarianship, v. 31, n. 5, pp. 432-437.

https://doi.org/10.1016/j.acalib.2005.05.004 
Whitchurch, Celia (2008). "Shifting identities and blurring boundaries: The emergence of third space professionals in UK higher education". Higher education quarterly, v. 62, n. 4, pp. 377-396.

https://doi.org/10.1111/j.1468-2273.2008.00387.x

World University Consortium newsletter (2014).

http://www.wunicon.org/files/newsletters/Newsletter_Dec_2014.pdf

\section{Appendix}

\section{Questionnaire A. Learning analytics' expert opinion elicitation}

1. Do you believe that European University in-library use data, in the way that are currently being collected and shared, can adequately assist faculty in supporting student success and retention?

2. How optimistic are you about the association of in-library use data to learning management systems and other student success related technologies?

3. How feasible do you consider systematizing student in-library use data collection (space use/ reference/instruction related etc.) for the benefit of learning analytics campus-wide programs?

4. On which level do you believe should in-library user activity data be better collected and analyzed? (e.g. personaIly-identifiable or aggregated, stand-alone or interconnected with wider learning analytics initiatives)

5. From a financial, technical, attitudinal and competential point of view, do you consider academic librarians capable to effectively cope with the implications and requirements of such innovation as their involvement in learning analytics interventions? Please, justify your answer.

6. What are the prospects for Higher Education administrators supporting joint library learning analytics initiatives?

7. Do you think students would welcome a library/faculty unified learning analytics initiative? What do you think they need to know in order to fully support it?

8. Do you have any practical or ethical considerations associated with the integration of library data to learning analytics initiatives?

\section{Questionnaire B. Greek academic library directors' opinion elicitation}

1. Do you believe that University in-library use data, in the way that are currently being collected and communicated to faculty, can adequately support student success and retention?

2. How feasible do you consider the process of systematizing student in-library use data collection (inter alia space/ facilities/equipment use, reference consultations, instruction and workshop attendance)?

3. On which level do you believe should in-library user activity data be better collected, analyzed and shared and why? (e.g. personally-identifiable or aggregated, stand-alone or interconnected with wider learning analytics initiatives, real time or periodic)

4. From a financial, technical, attitudinal and competential point of view, do you consider academic librarians capable to effectively cope with the implications and requirements of such innovation as their involvement in learning analytics interventions? Please, justify your answer.

5. Do you believe that the academic library is in the position to move to this transformation stage in terms of resources?

6. How do you think students would react to such an innovative collaboration between the library and faculty that would provide stakeholders with a concise view of student workflows within library walls? What do you think it would take to convince them of whatever usefulness this intervention may have on their progress?

7. What are the prospects for Higher Education administrators supporting the integration of library use data in campus analytics systems (predictive/learning analytics \& student success technologies)?

8. Do you have any practical or ethical considerations associated with handling library use data as educational data that could be used like other student performance data in the evaluation and support of student cognitive development and progress? If yes, what are these concerns about?

9. In view of a possible association of library use data with student support technologies and taking into consideration the current higher education scenario, which action do you believe would be of priority for the Greek context? [1] the formation of campus-wide student support coordination committees, [2] targeted communication activities especially concentrated in the dimensions, implications and prospects of library involvement in learning analytics projects, [3] the articulation of a regulatory framework covering these innovative interventions and [4] an extensive stakeholder opinion research on the usefulness, complexity, acceptance and feasibility of this type of initiatives 